\title{
Biopsychosocial perspective of ADHD
}

\author{
Luisa Matilde Salamanca
}

Universidad Autónoma de Manizales, Manizales, Colombia

Email: luisasalamanca@autonoma.edu.co

Received 18 October 2013; revised 18 November 2013; accepted 25 November 2013

Copyright (C 2014 Luisa Matilde Salamanca. This is an open access article distributed under the Creative Commons Attribution License, which permits unrestricted use, distribution, and reproduction in any medium, provided the original work is properly cited. In accordance of the Creative Commons Attribution License all Copyrights @ 2014 are reserved for SCIRP and the owner of the intellectual property Luisa Matilde Salamanca. All Copyright (C 2014 are guarded by law and by SCIRP as a guardian.

\section{ABSTRACT}

Attention Deficit Hyperactivity Disorder (ADHD) is considered a major public health problem, not only for its high prevalence but also because the symptoms have an impact on activities in daily life at both familial and school levels as well as on a general social level. Clinical evaluation of ADHD was based on the diagnostic criteria of the International Classification of Diseases ICD 10, Diagnostic and Statistical Manual of Mental Disorders DSM IV and comorbidity phenomena. Therefore, it has not yet developed into evaluations any more comprehensive than activity limitations and participation restrictions from a biopsychosocial model of disability, as proposed by the International Classification of Functioning, Disability and Health ICF. Thus, it is necessary to start assessment processes of children with ADHD using the functionality and performance components proposed by the ICF, allowing a new approach and a greater understanding of the health status of this population from a more holistic perspective in relation to the disability. Objective: To identify the theoretical elements that justify the importance of addressing ADHD from a bio-psychosocial perspective as proposed by the evaluation of the ICF model, ensuring comprehensive assessment processes. This article is the result of a theoretical review addressed in research projects around the design, validity and reliability of assessment instruments of activity limitations and participation restrictions in children with ADHD.

\section{KEYWORDS}

Attention Deficit Disorder with Hyperactivity ADHD; International Classification of Functioning; Disability and Health ICF; Children

\section{INTRODUCTION}

Attention Deficit Hyperactivity Disorder (ADHD) is de- fined as a common neurobehavioral syndrome characterized by hyperactivity, impulsivity and inattention, which affect the development of children [1]. It is the most common behavior problem of chronic nature in childhood [2,3], especially in the school years. It represents a complex problem because it appears at an early age, affects the daily lives of children from all areas of development [4] and is likely to persist throughout life [5]

In recent years, this disorder has been assumed as a major public health problem. The results of studies report a prevalence of $17.1 \%$, in which combined is the most common type (9.4\%), with a significantly higher presence in males $(21.8 \%)$ than in females $(10.9 \%)$, and ages between 6 and 11 have a more frequent diagnosis (22.6\%) [3].

The American Psychiatric Association APA [6] identifies three core symptoms: inattention, hyperactivity and impulsivity, but there can also be other associated manifestations such as comorbidity, including oppositional defiant disorder by 35\%, antisocial disorder by $25 \%$, anxiety disorder by $25 \%$, depressive disorder by $15 \%$, learning disorders by $15 \%$ - 40\%, and language disorders in $15 \%$ - 75\% [7]. These difficulties lead children to continuous experiences of failure, which may be more widespread in their family, educational and social contexts, presenting them with daily limitations in both functional activities and in social participation, restrictions which hamper personal and social functioning.

Under these criteria, ADHD has been approached for diagnosis basically from a clinic perspective, with a greater emphasis on the biological aspect and on consequences of the disorder from classifications ICD-10 [8], DSM-IV [6] and comorbidity phenomena [7], which are not directly framed into the current conceptualization of the bio-psychosocial model of the International Classification of Functioning, Disability and Health ICF of the World Health Organization WHO [9], under which health conditions should be regarded. 
The ICF describes human functioning as an umbrella term for body functions and structures, activities and social participation, indicating the positive aspects of the interaction of an individual in a specific health condition with environmental and personal contextual factors that determine it. From this perspective, CIE and ICF are complementary in combination. They enable a better analysis of the situation of children with ADHD.

In this regard, it is necessary to make an effort to design reliable tools that can assess the degree of interference with the adaptive functioning of the subject to different contexts [10], transcending the intervention to broader perspectives of health, child development and its various components.

For this reason, in 2009 in Manizales, Colombia, we designed a questionnaire to assess activity limitations and participation restrictions in children with ADHD, "Cuestionario para la evaluación de Limitaciones en la Actividad y Restricciones en la Participación en niños con TDAH, CLARP TDAH Parents Version and Teachers Version” [11,12] and in 2012 its psychometric properties were determined by internal consistency reliability, intra-rater reliability and concurrent validity; satisfactory results were obtained. In this last study, these questionnaires were administered to a convenience sample of 203 parents and teachers of children between 6 and 12 in the Colombian cities of Bogotá, Bucaramanga, Cali, Cartagena and Popayán. The data obtained were analyzed statistically with the SPSS software version 19.0 through descriptive and correlational analysis, using statistical tests such as Kappa $(\mathrm{k})$ to determine the degree of intra-rater reliability of the instruments, Cronbach's alpha to determine the internal consistency and concurrent validity using Spearman's correlation coefficient, and multiple and unique predictors through multiple and single linear regression models respectively. Regarding the results, CLARP TDAH Parents version showed a very good level of concordance with $\mathrm{k}$ values between ranges 0.639 and 0.857 , whereas CLARP TDAH Teachers version showed a very good concordance with $\mathrm{k}$ values between ranges 0.721 and 0.879 , $(\mathrm{Z}$ of $95 \%$ and $\mathrm{p}=0.000)$. Internal consistency assessed by Cronbach's alpha to the instruments was elevated as for each of its domains. CLARP TDAH Parents version showed good internal consistency with 0.83 . CLARP TDAH Teachers version had 0.93. Regarding concurrent validity with the Strengths and Difficulties Questionnaire SDQ Parents and Teachers, we found concurrence between CLARP TDAH Teacher version and Teacher SDQ. There was not concurrence between CLARP TDAH Parents version and Parents SQD. There is also concurrence between CLARP TDAH Parents version and CLARP TDAH Teachers version, which is given by values $\mathrm{p}<0.001$. Such study arose a base theoretical benchmark as a result of a litera- ture review and an analysis on the issue, which will be presented in this reflection paper.

\section{THEORETICAL FOUNDATIONS}

\subsection{Biopsychosocial Model and International Classification of Functioning, Disability and Health}

Currently, the ICF of the WHO [9] based on a biopsychosocial model describes human functioning as a generic term that includes three components: body functions and structures, activities, and social participation. All together, those components interact with environmental, contextual, and personal factors that determine human functioning, giving greater clarity and specificity to elements susceptible to be intervened in people, transcending not only to its functionality but also to its working in context. Thus, a comprehensive intervention and the development of actions and policies on those issues are promoted.

Functions are defined as the physiological functions of body systems, including psychological functions, body structures as anatomical parts of the body such as organs, limbs and their components, activity as the completion of a task or action by of a person, and participation as the act of engaging in a life situation.

Classification also addresses the term disability, which includes impairments in body functions and structures, activity limitations and participation restrictions, describing the negative aspects of such interaction. Impairments are problems in body function or structure such as a significant deviation or loss, whilst activity limitations are difficulties an individual may have in executing/implementing activities, and participation restrictions are problems an individual may experience in involvement in life situations.

Understanding this bipolarity performance-disability from the ICF, the classification is intended to reflect the real situation of human functioning, in which consequences of health and physical status, and social environment are definitely substantial.

This conceptual shift allows stating that with the ICF it is possible to evolve from a rating of "consequences of the disease" to a classification of "health components", with relevant aspects related to human welfare state. The term "health" has significance here within a conceptual framework that assesses the health and states related to it. The term "disease" in turn, is no longer used and is replaced by the term "health condition".

In this sense, it is feasible to assume that a child with ADHD is in a state of disability, since there are many shortcomings, functional activity limitations and social participation restrictions that prevent proper operation. 


\subsection{ADHD in the Framework of the ICF}

As mentioned above, ADHD as a clinical problem is considered in different classifications that establish its diagnosis and symptomatic characterization, providing an etiologic framework to the health status and morbidity conditions from public health. However, these classifications seem on their own seem not to cover the essential elements of the health status of children, proving insufficient to predict their needs in terms of services, intervention programs and public policies. Therefore, medical diagnosis in itself does not predict the needs that require a solution.

ADHD, as a clinical and behavioral entity may be considered likely to be approached from the biopsychosocial approach, since it is recognized that the basic neurobiological disorder is equally determined and influenced by other multiple external and environmental factors that can not only lead to a series of clinical symptoms but also to important implications from performance in daily, functional and social activities, and exacerbate these clinical manifestations and comorbidities in different contexts.

The broad and multidimensional framework of the ICF allows understanding and evaluating the performance in ADHD, covering more than the classic symptoms from brain function to daily activities and participation in society, involving family, school and everyday environment.

Cunningham [13] and Loe and Feldman [4], analyzed children with ADHD in their family and educational and academic relations, and they acknowledged that few studies address this problem from adaptive behavior and the effects of treatment on functional results. Hoza also [14] recognizes that diagnostic symptom criteria should be included into the functional and social impairment.

The evaluation and sometimes the diagnosis of ADHD rely heavily on information obtained from behavioral scales and checklists based on criteria established mainly in the DSM -IV, from specific clinical criteria that do not go beyond the level proposed by the ICF.

Accordingly, the ICF can be used to classify the symptoms of ADHD, for example, the central criterion of inattention can be evaluated in bodily functions such as attention focusing and distribution, short-term and longterm memory impairment, lack of psychomotor control, cognitive dysfunction greater in organization and planning, in time management, and in problem solving, among others. Other symptoms like hyperactivity, impulsivity and executive functions would be classified within organization, time management, cognitive flexibility, understanding, judgment, problem solving and complex movement sequence. From the section of body structures it would be classified as changes in brain volumes, caudate nucleus, corpus callosum, the frontal area of the basal ganglia and the cerebellum.

The activity limitations and participation restrictions of ADHD, such as problems that can be experienced in everyday situations can be included from the 9 chapters of the ICF: Learning and applying knowledge, general tasks and demands, communication, mobility, self-care, domestic life, interpersonal interactions and relationships, major life areas and community, social and civic life.

The classic symptoms of ADHD are classified as bodily functions and behavioral difficulties. Problems with socialization and family and school performance are seen as problems of activity performance and participation in the ICF. The contextual factor is added to this analysis, although the underlying dysfunction impact on daily activities depend largely on the severity of cerebral dysfunction, as well as external factors such as social and family characteristics and structure and organization of a classroom can disrupt the symptoms even more. Thus, in addition to activities and participation, the environment should be assessed separately, and the ICF provides a framework for analyzing the components of the disorder from the context. Considering the diagnostic criteria from the DSM -IV, criteria 2 and 3, changes in two or more stages and disruption in social, academic or occupational functioning add an element of environmental factors interacting with the symptoms [15].

\subsection{Body Functions and Structures of ADHD}

The scientific literature has identified certain neuroanatomical changes associated with ADHD, one of them is the right hemisphere dysfunction. According to Pueyo et al [16], the deficit of the right-side of the frontostriatal system causes the ADHD symptomatology. Research studies with different functional neuroimaging of regional cerebral metabolism in diagnosed participants showed hypoperfusion in the right striatum and hypoperfusion of the sensorimotor cortex region as well as an extensive reduction in glucose metabolism mostly marked in the premotor cortex and left frontal region. Besides it was found that the frontal region and the caudate are symmetrical in children with ADHD, in contrast to the observed asymmetry in normal participants (where the right side is larger than the left). Another finding is the inversion in the pattern of normal head asymmetry of the caudate nucleus, in ADHD the right is bigger than the left side. In general, there has been a reduction in global brain volume, lower right frontal region, smaller cerebellum and loss of the expected ventricular asymmetry (left is bigger than the right side). Other studies have shown that it has a lower brain volume of the right anterior and upper brain regions, anterior inferior bilateral and bilateral retrocallosum (parietal and occipital region).

ADHD must also be recognized as a disorder with a dominant executive dysfunction, some neuropsychologi- 
cal studies cited by Quintanar, Lazarus and Solovieva [17] indicate the relationship between this syndrome and the functional weakness of the frontal lobes, and specifically in the prefrontal cortex regions, which thanks to its continuous intercorrelation with the limbic system and the reticular formation makes possible the skills and abilities related to planning, programming, cognitive flexibility, working memory, behavior, control inhibitory impulse control, self-control behavior and monitoring and self-monitoring. These functions are necessary to improve the performance on a particular task, or to have the capacity to do it [18].

Among the best-documented prefrontal alterations, and also consistent with the clinical picture of ADHD have also been described by several authors: inability to plan behavior toward a goal, difficulties in programming actions to achieve a goal, inflexibility to correct mistakes or to incorporate new behaviors based on environmental stimuli and to complete the task when the objectives that have been achieved, little control of interference and irrelevant stimuli, alterations in working memory, language production, attention and abstract thinking. The emotional characteristics are also evident in this dysfunction, problems in processing emotional information, blankness, impulsiveness, irritability, social and interpersonal interactions desadaptation and changes in the behavior regulation and self-regulation.

According to Ustun [19] deficits in ADHD from the component body functions and structures with their coded according to ICF are:

-Neglect

b140

-Low surveillance

b1402

-Impulsivity

b1304

-Impaired short-term memory

b1440

-Impaired long-term memory

b1441

-Psychomotor disorder

b1470

-Higher cognitive dysfunction in organization and planning b1641

-Higher cognitive dysfunction in time management b1642

-Higher cognitive dysfunction in problem resolution b1646

-Lower brain volumes

s110

-Asymmetry of the caudate nucleus

s1103

-Size and shape of the corpus callosum

s11008

-Lower right front area

s11000

-Lower right basal ganglia

s1103

-Changes of the cerebellum

s1104

\subsection{Activities and Participation in ADHD}

The child may experience activity and participation limitations in ADHD in his daily life at home, school and society. Such difficulties are evident for example in personal activities as self-care, the ability to get ready in the

morning, in the day-to-day planning, organization of activities and tasks, chores, time management, school and educational activities, among others. It is also evident having difficulties in learning, performance in the classroom, chores accomplishment and academic performance. The child also presents alterations in interpersonal relationships because of impulsivity, poor listening skills and aggressiveness.

In addition Üstün proposes the following list of activities and participation that may be affected by ADHD:

\begin{tabular}{|c|c|}
\hline -Learning to read & $\mathrm{d} 140$ \\
\hline -Reading & d166 \\
\hline -Learning to write & d145 \\
\hline -Writing & $\mathrm{d} 170$ \\
\hline -Learning to calculate & $\mathrm{d} 150$ \\
\hline -Calculating & d172 \\
\hline -Listening & d115 \\
\hline -Focusing attention & d160 \\
\hline -Solving problems & d175 \\
\hline -Performing multiple tasks & d220 \\
\hline -Carrying out daily routine & d230 \\
\hline -Handling stress and other psychological & $\begin{array}{c}\text { demands } \\
\text { d240 }\end{array}$ \\
\hline -Communication & $\mathrm{d} 310$ \\
\hline -Speaking & d350 \\
\hline -Basic interpersonal interactions & d710 \\
\hline -Complex interpersonal interactions & d720 \\
\hline -Problems making friends & d7200 \\
\hline -Problems making friends & d7500 \\
\hline -Peer Relationships & d7504 \\
\hline -Family Relations & d760 \\
\hline -Completing tasks in school & $\mathrm{d} 210$ \\
\hline -Gentle in school & $\mathrm{d} 2400$ \\
\hline -Learning difficulties & d159 \\
\hline -Accuracy & $\mathrm{d} 160$ \\
\hline -Test taking & d175 \\
\hline -Control in social relati & d7103 \\
\hline -Stability in social relations & d7104 \\
\hline
\end{tabular}

\subsection{Contextual Factors in ADHD}

It is clear that ADHD, respect to the exacerbation and relief of symptoms, is modulated by the physical, social and attitudinal environment in which the person lives. Therefore, the analysis of both personal and environmental positive factors, as well as of the negative-barriers, is decisive in the analysis of the performance. Among the personal factors, there are others that are included related to the individual background of a person's life, others with health condition, such as gender, race, age, lifestyle, habits, education, way of dealing with problems, occupation, previous experiences, patterns of behavior, character, personality, and others. In the case of ADHD for example, being a boy or girl can make a difference in tolerance or in the modulation of behavior 
patterns associated with the disorder.

\section{CONCLUSIONS}

ADHD is a neurobehavioral disorder with genetic and neurobiological basis. At the same time, it impacts brain function affecting daily activities such as family, school, work and social life. Therefore, it is a significant source of disability condition. In any clinical disorder, medical diagnosis is not a sufficient predictor of the needs, use, costs and outcomes of health care. Therefore, to recognize the possible degree of disability from a biopsychosocial model constitutes a positive parameter that favors a better monitoring to the public health and the evaluation processes and results from interventions of people with ADHD.

As a tool accepted on an international level, the clinical and social use of the ICF is just beginning in Colombia, in the first steps towards future development in building tools and coding standards that allow the implementation of classification in different areas. In this long-term vision, we must be aware that its use will depend largely on its practical utility. The wide and multidimensional framework of the ICF allows for the understanding and evaluation of the disability and functioning of ADHD. Including more than just the classic symptoms of brain function, it also covers daily activities and participation in society, family involvement, and the school and the daily environment. It will also create a standardized, reliable and cross-culturally applicable language for describing human functioning and disability as important elements of health, using positive language and a universal vision of disability, in which these issues come from the interaction of individual characteristics with the environment and the social context.

\section{ACKNOWLEDGEMENTS}

Translation Center: Autonomous University of Manizales UAM. Translators: Olga Umaña Corrales and Inés Gabriela Guerrero. Reviser: Chris Cadman.

\section{REFERENCES}

[1] Arriada-Mendicoa, N. and Otero-Siliceo, E. (2000) Síndrome de atención deficitaria. Aspectos básicos del diagnóstico y tratamiento. Revista de Neurologia, 31, 845-851.

[2] Cornejo, J.W., Osío, O., Sánchez, Y., Carrizosa, J., Sánchez, G., Grisales, H., Castillo-Parra, H. and Holguín, J. (2005) Prevalencia del trastorno por déficit de atención-hiperactividad en niños y adolescentes colombianos. Revista de Neurología, 40, 716-722.

[3] Pineda, DA., Lopera, F., Henao, G.C., Palacio, J.D. and Castellanos, F.X. (2001) Grupo de investigación Fundema. Confirmación de la alta prevalencia del trastorno por déficit de atención en una comunidad colombiana. $R e$ vista de Neurología, 32, 1-6.

[4] Loe, I.M. and Feldman, H.M. (2007) Academic and educational outcomes of children with ADHD: Literature review and proposal for future research. Ambulatory Pediatrics, 7, 82-90.

http://dx.doi.org/10.1016/j.ambp.2006.05.005

[5] American Academy of Pediatrics (2001) Commitee on Quality improvement and subcommitte on attention-deficit/hyperactivity disorder. Clinical practice guideline: Diagnosis and evaluation of the child with attention- deficit/hyperactivity disorder. Pediatrics, 105, 1158-1170.

[6] American Psychiatric Association (1994) Diagnostic and statistical manual of mental disorders. 4th Edition, American Psychiatric Association, Washington DC.

[7] Roselló, B., Amado, L. and Bo, R.M. (2000) Patrones de comorbilidad en los distintos subtipos de niños con trastorno por déficit de atención con hiperactividad. Revista de Neurología Clínica, 1, 181-192.

[8] World Health Organization (1992) The tenth revision of the international classification of diseases and related health problems. WHO, Geneva.

[9] World Health Organization (2001) International classification of functioning, disability and health. WHO, Geneva.

[10] Cardo, E. and Servera, M. (2008) Trastorno por déficit de atención/hiperactividad: Estado de la cuestión y futuras líneas de investigación. Revista de Neurología, 46, 365372.

[11] Salamanca, L.M. (2010) Construcción, validación y confiabilidad de un cuestionario sobre niños y niñas con TDAH. Revista Latinoamericana de Ciencias Sociales, Niñez y Juventud, 8, 1117-1129.

[12] Salamanca, L.M. (2010) Cuestionario para la evaluación de limitaciones en la actividad y restricciones en la participación en niños con TDAH a nivel escolar. Revista Chilena de Psiquiatría y Neurología de la Infancia y adolescencia, 2, 19-30.

[13] Cunningham, C.E. (2007) A Family-centered approach to planning and measuring the outcomes of interventions for children with attention-deficit/hyperactivity disorder. Ambulatory Pediatrics, 7, 60-72. http://dx.doi.org/10.1016/j.ambp.2006.05.003

[14] Hoza, B. (2007) Peer functioning in children with ADHD. Ambulatory Pediatrics, 7, 101-106. http://dx.doi.org/10.1016/j.ambp.2006.04.011

[15] Lollar, D. (2008) Function, impairment, and long-term outcomes in children with ADHD and how to measure them. Pediatric Annals, 37, 28-36. http://dx.doi.org/10.3928/00904481-20080101-08

[16] Pueyo, R., Mañeru, C., Vendrell, P., Mataró, M., Estévez-Gonzalez, A., García-Sánchez, C. and Junqué, C. (2000) Trastorno por déficit de atención con hiperactividad. Asimetrías cerebrales observadas en resonancia magnética. Revista de Neurología, 30, 920-5.

[17] Quintanar, L., Solovieva, Y. and Lázaro, E. (2008) Mecanismos de los lóbulos frontales en niños preescolares con déficit de atención y niños normales. Acta 
Neurológica Colombiana, 24, 64-75.

[18] Pistoia, M., Abad-Mas, L. and Etchepareborda, M.C. (2004) Abordaje psicopedagógico del trastorno por déficit de atención con hiperactividad con el modelo de entrenamiento de las funciones ejecutivas. Revista de Neurología, 38, 149-155.
[19] Ustün, T.B. (2007) Using the international classification of functioning, disease and health in attention-deficit/hyperactivity disorder: Separating the disease from its epiphenomena. Ambulatory Pediatrics, 7, 132-139. http://dx.doi.org/10.1016/j.ambp.2006.05.004 